Recibido: 04/05/2021 --- Aceptado: 28/09/2021 --- Publicado: 10/12/2021

\title{
MÚSICA Y SONIDO EN LA POTENCIACIÓN DE UNA MARCA: EL CASO DE IKEA
}

\section{MUSIC AND SOUND FOR BRAND EMPOWERMENT: THE IKEA'S CASE}

D (3) Diego Calderón-Garrido²: Universitat de Barcelona. España. dcalderon@ub.edu

(3) Josep Gustems-Carnicer: Universitat de Barcelona. España. jgustems@ub.edu

\section{Cómo citar el artículo:}

Calderón-Garrido, D. y Gustems-Carncier, J. (2021). Música y sonido en la potenciación de una marca: el caso de IKEA. Revista de Comunicación de la SEECI, 54, 205-222. http://doi.org/10.15198/seeci.2021.54.e722

\section{RESUMEN}

Este trabajo pretende valorar la música y el sonido en la potenciación de las características de marca, tomando como ejemplo un anuncio de IKEA, retransmitido para la campaña de Navidad de 2018. Para ello se distinguen las emociones más relevantes, la orientación hacia al consumo, junto a una caracterización psicosocial de la marca. A través de un análisis multimodal, realizado por una muestra de 86 estudiantes del grado de cinematografía en la Escuela Superior de Cine y Audiovisuales de Cataluña que visualizaron repetidas veces dicho anuncio, se observó un predominio de la tristeza y el nerviosismo a través, no solo de las imágenes, sino del uso de una música ya usada en otros productos audiovisuales (Claire de Lune de C. Debussy), el uso de las voces y un uso estratégico de los silencios. Gracias al análisis multimodal se aprecia la orientación del anuncio hacia valores humanos, así como cierta preponderancia de los jóvenes y de las mujeres en el interés a esta marca, a través del uso del sonido.

${ }^{1}$ Diego Calderón-Garrido: Doctor en Historia del arte. Doctor en Tecnología Educativa. Serra Húnter Fellow en la Universitat de Barcelona, Facultad de Educación, Departamento de Didácticas Aplicadas.

Correo: dcalderon@ub.edu 
PALABRAS CLAVE: Multimodalidad - Música- Sonido - Publicidad - IKEA - Redes Sociales - Emoción.

\section{ABSTRACT}

This paper aims to assess the music and the sound in the enhancement of brand characteristics, taking as an example an ad from IKEA, broadcast for the Christmas campaign 2018. For this aim, we distinguish the most relevant emotions, the orientation towards consumption, together with a psychosocial characterization of the brand. Through a multimodal analysis, carried out by a sample of 86 students of the degree of cinematography at the Higher School of Cinema and Audiovisual of Catalonia who repeatedly visualized this announcement, a predominance of sadness and nervousness was observed through, not only images, but the use of music already used in other audiovisual products (Claire de Lune de C. Debussy), the use of voices and a strategic use of silences. Thanks to multimodal analysis, the orientation of the ad towards human values is appreciated, as well as a certain preponderance of young people and women in the interest to this brand, through the use of sound.

KEY WORDS: Multimodality - Music - Sound - Advertising - IKEA - Social Media Emotion.

\section{MÚSICA E SOM NA MELHORIA DE UMA MARCA: O CASO DA IKEA}

\section{RESUMO:}

Este trabalho visa valorizar a música e o som na valorização das características da marca, tomando como exemplo um anúncio da IKEA, veiculado para a campanha de Natal 2018. Para isso, distinguem-se as emoções mais relevantes, a orientação para o consumo, a par de uma caracterização psicossocial da marca. Através de uma análise multimodal, realizada por uma amostra de 86 alunos do curso de cinematografia da Escola de Cinema e Audiovisual da Catalunha que assistiram repetidamente ao referido anúncio, observou-se um predomínio da tristeza e do nervosismo, não só pelas imagens, mas pelo uso da música já utilizada em outros produtos audiovisuais (Claire de Lune de C. Debussy), o uso de vozes e um uso estratégico de silêncios. Graças à análise multimodal, aprecia-se a orientação da publicidade para os valores humanos, bem como uma certa preponderância de jovens e mulheres no interesse por esta marca, através do uso do som.

PALAVRAS-CHAVE: Multimodalidade - Música - Som - Publicidade - IKEA - Redes Sociais - Emoção.

\section{INTRODUCCIÓN}

Este trabajo se centra en el estudio del sonido y la música en la publicidad audiovisual en el ámbito de la publicidad. Para ello se aplica una mirada multimodal que permita establecer relaciones entre la imagen, el sonido y las intenciones comunicativas de una marca publicitaria. En este caso el estudio se centra sobre una 
campaña de IKEA. Para poder analizar los mecanismos publicitarios se puede partir de la Teoría Multimodal, que se basa en que la comunicación sucede simultáneamente e integrada a través de diferentes canales o modos de significación (texto, imágenes, gráficos, diseño, sonido, música, gesto, habla, banda sonora, 3D, etc.) (O'Halloran, 2008).

De esta forma, la publicidad entendida como transmisora de una imagen de marca, forma de vida y valores, adquirirá todo su sentido, presentará una nueva forma de relacionarse con el público (Cluley y Nixon, 2019), un cambio que impregnará todo el discurso: argumentos, textos, sonidos, músicas, personajes, edades, sexos, colores, paisajes, etc. Se trata de un relato interdisciplinar que fortalecerá a su vez el mensaje de marca, y donde la música y el sonido tendrán una notable influencia. La publicidad, persigue la efectividad en sus expresiones, por lo que un análisis que incluya dimensiones sonoras y psicosociales podría indicar cuáles son los mejores recursos en que apoyar futuras campañas. Entre estos destacan los contenidos emocionales para fortalecer la imagen de marca. Algunas buscan profundizar en esta dimensión emocional (Nardone y Salvini, 2006), para fidelizar a los consumidores a través de procesos de identificación estética proponiendo en muchos casos referencias sensoriales (Sánchez Porras, 2013).

La publicidad televisiva utiliza música en más del $97 \%$ de los anuncios (Sedeño, 2011). En sus bandas de sonido se aprecian ciertas tendencias comunes: silencios como separadores entre escenas; cambios de intensidad para evitar la saturación o la pérdida de inteligibilidad de las voces; uso estereotipado de algunos instrumentos musicales; uso generalizado de acordes consonantes y modo mayor; disonancias para captar la atención o señalar conflicto; ruidos contextualizadores, descriptivos y realistas; voces habladas masculinas o femeninas, según el target, sector productivo o contexto de consumo; músicas e instrumentos tradicionales con marcado sesgo cultural; estilos y géneros musicales en función de las características sociodemográficas del público objetivo, etc. (Gustems, 2005). En este sentido, no se puede obviar que la publicidad se aprovecha de la relación flexible entre significado y significante que el sonido proporciona, de forma que el emisor decide en que porcentaje el hecho sonoro es más o menos natural (icónico) y más o menos arbitrario (simbólico) (Rodríguez Bravo, 1998).

En el audiovisual, gracias a la experiencia de una inmersión atenta con cierto aislamiento, induciendo emociones intensas e íntimas (van Leeuwen, 2017), las diferentes reacciones emocionales dan lugar a respuestas neurofisiológicas, conductuales y cognitivo-verbales propias de cada emoción. Tales respuestas pueden caracterizarse según dos dimensiones principales: la denominada "valencia" (sensación de bienestar/malestar) y el arousal (relajación/activación) (Russell, 1980). Estos dos parámetros se combinan provocando 4 grandes polos emocionales: la calma (bienestar con poca activación), el entusiasmo (bienestar con mucha activación), la tristeza (malestar con poca activación) y la ira (malestar con mucha activación) (Diener y Emmonts, 1984) (ver Figura 1). Las emociones que despierten los anuncios en los espectadores vendrán enmarcadas por el bienestar y la excitación que nos hagan sentir, y de cómo estos factores se conjuguen entre sí. 


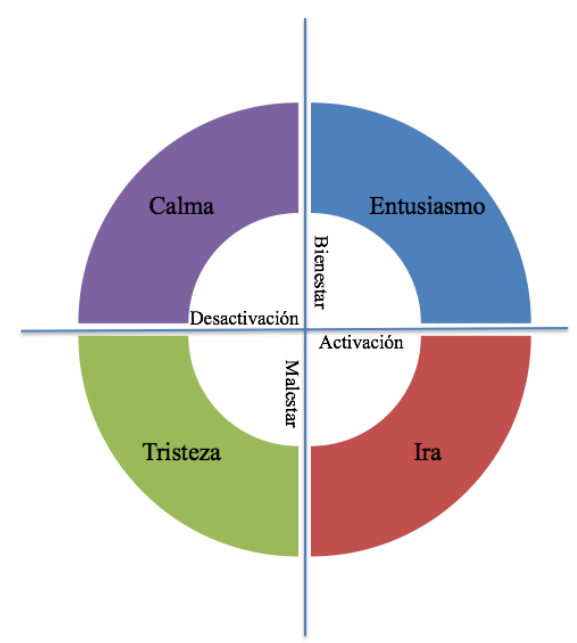

Figura 1: Modelo circunflejo de las emociones.

Fuente: Los autores, adaptado de Russell (1980).

El objeto escogido para esta investigación se centra en las emociones de la Navidad y cómo una marca puede utilizar enfatizar la música y el sonido para sus fines comerciales. La Navidad es un momento álgido de emociones debidas a la cercanía de los seres queridos, el recuerdo del año que está a punto de terminar, tradiciones de cada cultura que hacen especial esta época, simbolismo que, en muchas ocasiones, tienen también una orientación consumista que la publicidad navideña se encarga de vehicular.

Los anuncios navideños se revisten de buenas maneras, modales refinados, acompañados de música clásica o tradicional, combinando alegría y nostalgia mediante escenas de encuentros familiares, viajes de vuelta a casa, reuniones en espacios cerrados, donde el ambiente creado por las luces, el mobiliario y el diseño es clave para el confort y la calidez. Ese contexto es óptimo para que marcas como IKEA estén presentes, para que se asocie su marca a las emociones de este contexto y se refuerce su imagen de marca.

En 2018, IKEA presentó un anuncio en español (Familiarizados) especialmente pensado para el ámbito virtual y las redes sociales, en el que se centrará este trabajo. IKEA instó a los espectadores a reflexionar sobre su comportamiento respecto a los móviles y las redes sociales. Es más, apostó por una alternativa valiente mediante el gesto de desconectarse del mundo digital para reconectarnos con el mundo real, propuso interrumpir la actividad en redes sociales durante el periodo central de las navidades y proponía en el anuncio que sus protagonistas también lo hicieran, durante un rato. Este era el mensaje fundamental del anuncio, una campaña de refuerzo de marca más que a venta de producto, alejándose de otros anuncios convencionales de mobiliario, que anuncian un producto y provocan el deseo de su adquisición entre los consumidores (Norton et.al., 2012). En este, aparentemente, no se anunciaba nada. Sin embargo, apelaba a algo que en la 
publicidad se ha mostrado como esencial: la sensación de identificación con lo que está pasando en el anuncio como refuerzo de nuestras propias emociones (Park y Lee, 2014). En este caso, la consciencia colectiva de que las redes sociales invaden nuestras vidas sustituyendo nuestra propia realidad.

Esta forma de publicidad en la que la historia sustituye al producto ha sido estudiada por investigadores como Coker, Flight y Baima (2021), quienes demostraban que la publicidad que narrativa enganchaba más a los espectadores que la argumentativa. Dicho formato era también más compartido y recordado. Conclusiones parecidas, pero en formato radiofónico, fueron las que obtuvieron Kang, Hong y Hubbard (2020), quienes hicieron hincapié en el impacto emocional que las historias narradas en publicidad (por ejemplo, sobre el fundador de una marca) tenían en los espectadores. De esta forma nos adentramos en el denominado storytelling (Yang y Kang, 2021). A través de anuncios distribuidos por las redes sociales, en formato historia cargados de sentimientos en los que los espectadores se encuentran reflejados, el publicista pretende crear una imagen de marca que se convierta en algo más que esa "simple marca" y pase a ser una forma de ser (YIImaz y Enginkaya, 2015), algo que identifica al usuario y que, por tanto, hace que este sea un auténtico emisario de dicha marca (Roberts, 2005). No en vano, las redes sociales están cargadas de historias personales, por lo que las historias ofrecidas por las diferentes agencias de publicidad se mezclan con las que los usuarios comparten, tomando aún más sentido la expresión de "prosumidores".

Respecto a IKEA, aunque se fundó en 1943, busca la co-creación de valor como estrategia empresarial (Edvardsson, Enquist y Hay, 2006), una innovación que permite al cliente compartir parte del transporte y montaje de los muebles, y el ahorro correspondiente. Los cambios en el consumo y significado de sus productos han evolucionado junto con IKEA, a través de conceptos como "estilo de vida" o "capacidad de elección" (Machin y van Leeuwen, 2007).

El diseño del espacio y el mobiliario pueden comunicar ideas y mensajes claros sobre las identidades y relaciones sociales que representar y valorar (Aiello y Dickinson, 2014). Esto presenta un enfoque semiótico social mediante el que IKEA se alinearía también con ideas y valores tales como "flexibilidad", "dinamismo" "solución", "creatividad" o "autogestión" (Ledin y Machin, 2018). Otros elementos sociales asociados al receptor tendrían que ver con la identificación con los personajes y actores, su sinceridad, la empatía generada, sus distintos sexos y edades, etc. De esta manera la mayoría de los espectadores pueden sentirse identificados con algún personaje. Esta empatía establecida entre el anunciante y el posible consumidor se ha mostrado como clave en anteriores campañas publicitarias (Ribeiro-Cardoso, Vieira y Serra, 2019). Para conseguir estas implicaciones sociales el formato del anuncio recuerda otros concursos televisivos, con un plató interior y cámaras que recogen todos los ángulos. Junto a estas mesas se encuentra un espacio para la reflexión sincera dirigida al espectador (tipo "confesionario" de algunos programas televisivos), lo que implicaría la adopción de nuevos roles, responsabilidades, creencias y normas para sí mismos y para los demás. 
Así IKEA haría cosas "con" los clientes y no solo "para" los clientes (Gummesson et.al., 2014), un planteamiento que exigirá un nuevo marketing, más centrado en los interesados.

\section{OBJETIVOS}

Con toda esta información, nos planteamos hasta qué punto IKEA, estaría utilizando eficazmente el poder del sonido (música, voces y ruidos) en su publicidad audiovisual. El objetivo de este estudio, pues ha sido analizar el papel del audio en la caracterización psicosocial y emocional que se desprenden del anuncio Familiarizados (2018) de IKEA, a través de un análisis multimodal.

\section{METODOLOGÍA}

Este trabajo es de carácter analítico descriptivo, combinando datos cuantitativos y cualitativos, con una intención prospectiva y exploratoria. Para ello se ha analizado el anuncio Familiarizados (IKEA, Navidad 2018), creado en la agencia McCann, en su versión larga de tres minutos.

El análisis fue realizado por 86 alumnos (37 mujeres y 49 hombres) de primer semestre del grado de Cinematografía de la ESCAC (Escuela Superior de Cinema y Audiovisuales de Cataluña) de edades comprendidas entre los 18 y 22 años ( $M=$ 19.4; SD $=0.8$ ). Dichos alumnos no han cursado aun ninguna asignatura de análisis fílmico, solo de análisis sonoro.

Para dicho análisis se eligió la multimodalidad como modelo de estudio, y para ello se partió de las propuestas iniciales de Halliday (1978) y posteriores de Kress y van Leeuwen (2001) para construir una ficha multimodal ad hoc (Tabla 1), que incluía un nivel discursivo, otro de carácter social (distinguiendo entre emisor y receptor) y un último nivel mucho más detallado, donde se describían e incluían los elementos sonoros característicos del producto. En el nivel textual, solo se presentan los elementos sonoros, que son los que se quieren analizar en este trabajo. 
Calderón-Garrido, D. y Gustems-Carncier, J. Música y sonido en la potenciación de una marca: el caso de IKEA

Tabla 1: Propuesta de análisis multimodal para productos audiovisuales.

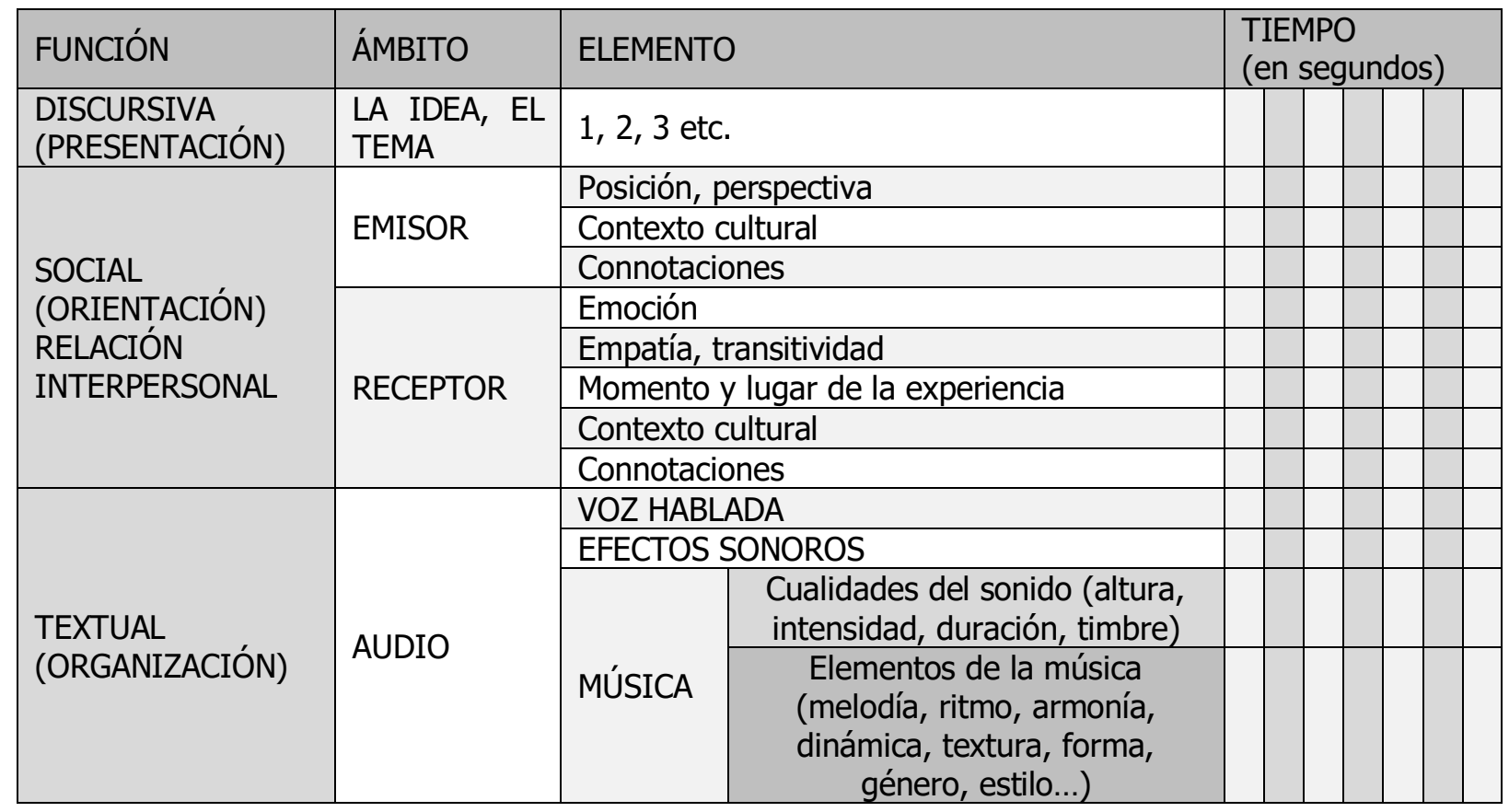

Fuente: Los autores, adaptado de Halliday y Kress y van Leuwen (2001).

Por otro lado, y para poder analizar las emociones provocadas se utilizó un instrumento de medida inspirado en el 2DES (Two Dimensional Emotion Space) y el Emotion Space Labe (Schubert, 1999). Cada estudiante señaló un punto en una hoja con dos ejes de coordenadas en forma de cruz, que recogía la valencia (eje vertical) y el arousal (eje horizontal) percibidos al finalizar el anuncio (ver Figura 2),

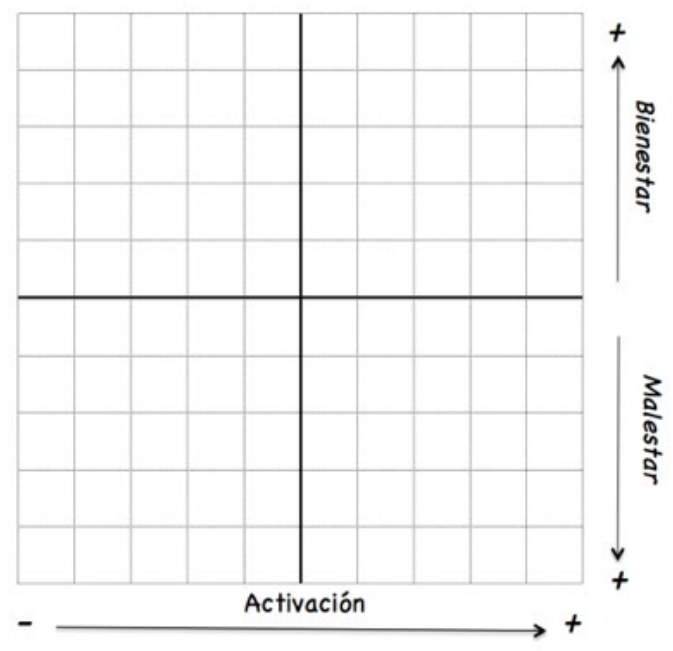

Figura 2: Modelo gráfico 2DES, adaptado a esta investigación-

Fuente: Los autores. 
A cada punto marcado se le otorgó un valor de dos coordenadas, de forma que el punto $(0,0)$ correspondería al de mínima activación y máximo malestar, el punto $(5,5)$ sería el centro de la cruz y el punto $(10,10)$ correspondería al de máxima activación y máximo bienestar. Los cuatro extremos del cuadrado corresponderían respectivamente a: tristeza $(0,0)$, ira $(10,0)$, entusiasmo $(10,10)$ y calma $(0,10)$. Todos los puntos señalan una emoción siguiendo el esquema propuesto por Russell (1980).

La ficha de análisis multimodal fue contestada por todos los participantes en una única sesión mediante siete visualizaciones colectivas. Los resultados fueron cotejados por dos especialistas en sonido y análisis multimodal.

Así mismo los participantes contestaron al modelo 2DES y finalmente, para obtener información sobre los estímulos sonoros implicados, se les pidió que dijesen los tres elementos sonoros presentes en el anuncio, y a su parecer, responsables de su valoración emocional.

Con todos los datos recogidos, se elaboró un fichero anónimo que incluía el sexo del participante, la valencia y arousal percibidos, y los tres elementos sonoros que consideraba más relevantes en su emoción. Todos los resultados obtenidos fueron plasmados en una ficha multimodal colectiva que recogía los datos de carácter emocional, junto con datos de fuentes sonoras, discursivas y sociales.

\section{RESULTADOS}

En primer lugar, cabe resaltar el formato y duración del anuncio, que presentaba tres partes diferenciadas de un minuto de duración cada una, que coincidían con las tres partes clásicas de las obras de teatro (presentación, nudo y desenlace).

A nivel discursivo, el tema del anuncio señala una paradoja: el poco conocimiento que se tiene de personas de nuestro entorno familiar en comparación con lo mucho que conocemos de personas ajenas a nosotros como son los protagonistas de las redes sociales.

A nivel social, el anuncio sitúa al espectador en un concurso televisivo que simula una cena de Navidad, con varias familias españolas actuales de clase media. No aparece ningún vendedor, ni llamada a la compra de ningún producto, sino que el interés comercial es sustituido por las relaciones humanas y los valores familiares de la Navidad. Cada uno de los grupos familiares del anuncio está compuesto por unas ocho personas de varias generaciones, sexos, edades y situaciones personales, aunque con un sesgo hacia la típica franja de clientes de IKEA (jóvenes y adultos jóvenes), y una menor presencia de ancianos respecto a la proporción en nuestra sociedad actual. Cabe destacar en este sentido que el concepto de "familia" se presenta ligeramente ampliado, al incluir varias generaciones en una misma mesa, lo cual, sin embargo, no deja de ser habitual en las fechas en las que se representa el anuncio. 
Por lo que se refiere a las connotaciones sociales, en las distintas mesas encontramos decoración de algunos programas de gran audiencia. La propia estructura del programa recuerda a concursos actuales.

Respecto a la música de la pieza audiovisual, se aprecian dos partes muy diferenciadas: el inicio con un estilo electrónico seguido de música para piano del compositor impresionista Claude A. Debussy, cuyo centenario de su muerte (1918) se celebraba ese mismo año.

Respecto a la música de la primera parte del anuncio, cabe destacar el uso de sintetizadores con sonidos electrónicos para ambientar el concurso, música incidental sin diseños ni incisos melódicos, salvo un guiño a la pieza de piano que seguirá. Este se trata de un intervalo de $3^{a}$ menor descendente que se escucha en los primeros segundos, típico del canto del cucú y que aparecerá al inicio de Claire de lune, la pieza que acompañará la mayor parte del anuncio. Esta música de Debussy ocupa la mayor parte del anuncio (118 segundos de 184 totales, unos 2/3 aproximadamente), la destinada a las revelaciones y sinceridad con mayor contenido emocional.

La elección del piano como instrumento exquisito, poderoso, complejo y a la vez nítido, propio de clases sociales altas, tocado a modo de arpa o laúd, aprovechando el pedal de resonancia, el modo menor, casi triste... los pájaros que cantan (como el cucú...) pintan un escenario de naturaleza y nocturnidad, donde se persigue el mundo interior a través del uso de la resonancia, como un subjetivismo envolvente, de claros tintes románticos.

Sin embargo, la música original ha sido adaptada para poder ensamblarse fácilmente en el guion del anuncio: eliminación de los ocho primeros compases, creación de un puente a base de arpegios después del compás 22 , repetición en octava alta de los compases 9 a 11, continuación en el compás 25 hasta el 31 y final con los compases 35 y 36 cortados bruscamente, dando sensación de que no se ha llegado a un final sino que la historia continua, igual que la vida de los personajes.

A nivel semiótico, podríamos hablar de diferentes niveles de lectura que permitirían una aproximación diferente al espectador que no conoce la pieza, a quien conoce la pieza pero no ha visto las películas, y a quien ha visto parte-totalidad de las películas.

Respecto a la emoción global provocada en el receptor al finalizar el anuncio, la más consensuada fue la tristeza, seguida del nerviosismo (en hombres), aunque sin apreciarse diferencias estadísticas en función del sexo (ver Tabla 2). 
Tabla 2: Emociones percibidas en el anuncio, según sexos

\begin{tabular}{|l|l|l|l|}
\hline EMOCIONES & N TOTAL (\%) & N (\%) hombres & N (\%) mujeres \\
\hline Asombro & $4(4.7)$ & $2(4.1)$ & $2(5.4)$ \\
\hline Entusiasmo & $3(3.5)$ & $2(4.1)$ & $1(2.7)$ \\
\hline Felicidad & $9(10.5)$ & $6(12.2)$ & $3(8.1)$ \\
\hline Relajación & $7(8.2)$ & $3(6.1)$ & $4(10.8)$ \\
\hline Tranquilidad & $11(13.7)$ & $7(14.3)$ & $4(10.8)$ \\
\hline Aburrimiento & $2(2.3)$ & $2(4.1)$ & $0(0)$ \\
\hline Tristeza & $31(36)$ & $15(30.6)$ & $16(43.2)$ \\
\hline Nerviosismo & $19(22.1)$ & $12(24.5)$ & $7(18.9)$ \\
\hline TOTAL & $86(100)$ & $49(100)$ & $37(100)$ \\
\hline
\end{tabular}

Fuente: Los autores.

Respecto a los principales elementos sonoros que provocaron y fueron responsables de dichas emociones, los participantes señalaron los que se muestran en la Tabla 3.

Tabla 3: Elementos sonoros responsables de las emociones, según los participantes

\begin{tabular}{|l|c|c|c|}
\hline Ámbito sonoro & Elementos sonoros & No de respuestas & TOTAL \\
\hline Música & Timbre (piano + sintetizador) & $54(44+10)$ & \\
& Sin concretar (música en general) & 47 & \multirow{2}{*}{130} \\
\cline { 2 - 3 } & Ritmo, tempo, cambios de tempo & 17 & \\
\cline { 2 - 3 } & Altura (armonía, melodía) & 12 & \multirow{2}{*}{66} \\
\hline \multirow{2}{*}{ Voces } & Actores y palabras & 35 & 18 \\
\hline & Voz intradiegética con reverberación & 31 & 16 \\
\hline Silencio & Silencio & 18 & 16 \\
\hline Ruidos & Risas, aplausos, murmullos, etc. & 16 & \\
\hline
\end{tabular}

Fuente: Los autores

Otros elementos sociales asociados al receptor, según comentan los participantes, tendrían que ver con la identificación conseguida con los personajes y actores, la sinceridad con la que éstos se expresan, mirando a cámara, sollozando, con las voces a punto de romper, la empatía generada, el hecho de que haya personajes de distintos sexos y edades, etc.

Respecto a las voces, tenemos las de los actores y la voz del speaker del concurso, acusmática, incorpórea pero intradiegética. Respecto a los actores cabe destacar que no son conocidos por lo que sus voces representarían aun mejor a cualquier familia española. En la primera y segunda partes del anuncio (minutos 0 al 2 ), aparecen por igual número voces de hombres y de mujeres, aunque con un pequeño sesgo respecto a los jóvenes (65\% frente al $35 \%)$. En la $3^{\mathrm{a}}$ y última parte del anuncio, en cambio, se escuchan (y se ven) muchas más mujeres que hombres ( $80 \%$ frente al $20 \%$ ), dato que coincide con un énfasis en expresión emocional en el guion. Además, en esta $3^{a}$ parte los personajes que aparecen van de mayor edad a 
menor, acabando con los más jóvenes, en concreto una niña que es la encargada de dar el mensaje del anuncio.

Respecto a la voz del speaker, se trata de un actor conocido en el ámbito cinematográfico español, tanto en su faceta de intérprete como de doblaje. Es un actor joven, dinámico, de tesitura barítono, común en las voces intradiegéticas de los concursos. Además, es importante el tratamiento con reverberación a esta voz.

Otro elemento importantísimo es el uso de una marcada disminución de intensidad y ritmo de casi 10 segundos como separador entre escenas (partes 1 y 2 ) y que, a su vez, plantea un cambio temático y emocional.

El resto de los elementos sonoros (ruidos, palmas, murmullos, etc.) son elementos contextuales descriptivos propios de la situación, sin contenido narrativo, más allá de confirmar las imágenes.

\section{DISCUSIÓN}

Por lo que se refiere al formato y la duración, tal como se ha reflejado difiere de la publicidad televisiva tradicional. La división en tres partes y la extensión se aleja de los entre 10 y 120 segundos habituales (Escribano, Fuentes y Alcaraz, 2006). Así pues, el audiovisual analizado estaría más cercano a los storytellings que a los spots tradicionales para televisión. De esta forma, con anuncios más largo, la marca puede recurrir a los sentimientos de los espectadores con historias desarrolladas (Yang y Kang, 2021).

A nivel discursivo, la paradoja que presenta pretende provocar en el espectador una reflexión hacia las personas realmente importantes para nosotros: la familia, abandonando por un corto espacio de tiempo el contacto con las redes sociales mediante el acto simbólico de guardar los móviles dentro de una caja. Esta paradoja evidencia el posible abuso e incluso adicción a las redes sociales de muchas personas en nuestra sociedad (Isidro y Moreno, 2018).

Respecto a la música, el estilo electrónico de la primera parte emula los concursos televisivos actuales (Nowak, 2018) seguida de una adaptación del Claire de lune de Debussy. Dicha pieza es una adaptación del 30 movimiento de la famosa Suite Bergamasque, de Debussy, publicada en 1905 e inspirada en un poema de Verlaine del mismo título. La pieza es suficientemente conocida para otorgarle cierta sofisticación, aunque lo suficientemente desconocida como para no quedar sujeta a demasiados recuerdos o vinculaciones preexistentes (Griffiths y Reay, 2018). El hecho de estar escrita en estilo impresionista puede ejercer un efecto sobre el oyente a través de elementos algo indefinidos, una impresión emocional efectiva, aunque difusa, difícil de explicar y delimitar (Strobel, 1990).

Esta pieza de Debussy, considerada una obra de repertorio (Alcalde, 2007) ha sido utilizada en obras cinematográficas emblemáticas de muy diversa consideración, lo que le confiere un valor añadido como recordatorio e imán. Entre las más destacadas 
tenemos: Siete años en el Tibet (J. J. Annaud, 1997), con Brat Pitt, donde se oye un fragmento de la pieza en una cajita de música; Dog Soldiers (N. Marshall, 2002), película de terror británica; El fuego de la venganza (T. Scott, 2004), un thriller trepidante protagonizado por Denzel Washington; Eclipse (D. Slade, 2010), de la saga Crepúsculo; Ocean's Eleven (S. Soderbergh, 2001) y Ocean's Thirteen (S. Soderbergh, 2007); Hannibal (R. Scott, 2001), con un impresionante Anthony Hopkins; la serie The Blacklist (2016); y en el mundo de la animación, Phineas y Ferb (2013), y The Simpsons en el episodio He loves to fly and He D'ohs.

Más allá de la tristeza, esta música ha sido asociada a la simplicidad, el mundo infantil, el canto del cucú, las navidades, las emociones intensas, el terror e incluso el humor y la sátira. Una breve lectura al poema de Verlaine, escrito en 1869, que inspira la obra, nos sitúa frente a determinados conceptos que generan impresiones serenas, magníficamente dibujadas en la obra de Debussy:

Votre âme est un paysage choisi que vont charmant masques et bergamasques jouant du luth et dansant et quasi tristes sous leurs déguisements fantasques. Tout en chantant sur le mode mineur l'amour vainqueur et la vie opportune ils n'ont pas l'air de croire à leur bonheur et leur chanson se mêle au clair de lune. $\mathrm{Au}$ calme clair de lune triste et beau, qui fait rêver les oiseaux dans les arbres et sangloter d'extase les jets d'eau, les grands jets d'eau sveltes parmi les marbres.

El uso de música preexistente en los anuncios es una constante de la publicidad televisiva, según nos advierte en su estudio Palencia-Lefler (2010), afirmando que el $50 \%$ de dichas músicas lo eran, siendo, sin embargo, más habitual el uso de músicas populares urbanas como parte de esas músicas de repertorio. Sin embargo, el uso de esta obra en los filmes señalados anteriormente hace que esta pieza pueda ser atractiva para los oyentes, pues le otorgan ciertos rasgos de familiaridad (North y Hargreaves, 1995). En este sentido, el uso de música preexistente en audiovisuales (Alcalde, 2007) aporta nuevas lecturas y significaciones a la imagen, aunque el atractivo sea propio de la pieza y no de su relación con otros "textos".

Como se ha descrito, el sentimiento mayoritario fue de tristeza, una emoción que lleva al recogimiento, a la reflexión y a cierta inacción, siendo una de las vivencias de las navidades, a pesar de los frecuentes eventos familiares. En algunos casos, la tristeza extrema, puede inducir incluso al suicidio (González-Abarca, et al., 2014), algo que lamentablemente crece en las fiestas navideñas (Hernández, 2018). Ese componente de tristeza, según Bruner (1990) es lo que más incita al consumo de productos. La tristeza es una emoción expresada en las artes preferentemente por el cine, la música y la literatura, según datos de la investigación de Calderón, Gustems, Martín, Fuentes y Portela (2020), por lo que resulta familiar a la audiencia. No se señalan diferencias respecto al sexo, confirmando estudios previos en los que se parte de la base de que hombres y mujeres, a pesar de sus diferencias neurológicas perciben de forma similar la mayoría de las artes y emociones que suscitan (Fedrizzi, 2012), rebatiendo así algunos estigmas sociales y prejuicios relacionados con estereotipos de género en la percepción emocional. En este caso, la tristeza viene reforzada por cierto sentimiento de culpabilidad que puede sentir el espectador al identificarse con los protagonistas del anuncio y comprobar que, al igual que estos, 
es más habitual conocer datos sobre la vida de los famosos a través de las redes sociales que de nuestros propios familiares.

Como se ha podido observar, además de la música, los participantes destacaron las voces, los silencios y los ruidos como responsables del impacto emocional en el anuncio, más allá del contenido explícito. Además, las características de la música implicadas en las emociones van en la línea de los resultados de Juslin y Sloboda (2001) y el metanálisis de Livinsgton y Thompson (2006), asociándola a elementos como la complejidad, altura, modo y tempo.

Por lo que se refiere a la identificación con los protagonistas, la gran mayoría de espectadores podrían sentirse identificados con alguno de los personajes que, de modo global, están de acuerdo con el tema y la situación. Esta empatía que se establece entre el anunciante y el posible consumidor se ha mostrado como clave en anteriores campañas publicitarias (Ribeiro-Cardoso, Vieira y Serra, 2019).

Respecto a la voz del speaker, el uso de una voz grave le confiere cierto poder de seguridad, serenidad y justicia otorgada a esta tesitura, pues algunos estudios constatan que las voces graves se usan preferiblemente para transmitir serenidad, templanza y una cierta añoranza (Melgar, 2019). El uso de la reverberación en esta voz puede generar cierta sensación de trascendencia, aumentada por el hecho de coincidir con diversos planos cenitales y su relación temática con la Navidad. La asociación de la resonancia con intenciones trascendentes y rituales está documentada desde el arte rupestre (Díaz-Andreu y García Benito, 2013) y en este caso podemos sugerir que guardaría cierto simbolismo con la conciencia.

Por otro lado, la marcada disminución en intensidad y ritmo antes de la segunda parte y el contraste que provoca (quizás con "efecto silencio") prepara también como lo hacían los silencios en los rituales religiosos de los antiguos romanos- para el contacto con la divinidad, de modo que la $2^{\mathrm{a}}$ parte del anuncio se plantea desde un posicionamiento mucho más trascendente. Este silencio, tal como describía Chion (1993), no funciona como un vacío, sino como un negativo del sonido, acentuando así la función de contraste. Además, es muy habitual en los concursos, incrementando el suspense sobre la pregunta y el posible fallo/acierto de la persona a la que se dirige. A esto ayudan los contraplanos de las personas y a su vez, contribuye a la creación de la paradoja.

\section{CONCLUSIONES}

El objetivo de este estudio era analizar el papel del sonido en la caracterización psicosocial y emocional del anuncio Familiarizados (2018) de IKEA a través de un análisis multimodal. En el anuncio analizado se han observado muchas coincidencias que enfatizan el sentido simbólico de los sonidos utilizados, orientados a perseguir una emoción, cierta tristeza apuntalada por la culpa reflejada en el guion del anuncio, que profundiza en los valores familiares, sobre todo durante las navidades. 
Para IKEA, el marketing implica, entre otros, enfatizar la percepción del cliente sobre la creación de valor, que también se refleja en la cultura y valores corporativos (Edvardsson, Enquist y Hay, 2006). La publicidad tradicional busca mover al público hacia la adquisición de productos, pero en este anuncio, aparentemente no se anuncia nada, pues es una comunicación sobre la marca, simplemente pasar más tiempo con la familia y prescindir de las redes sociales en Navidad, aludir solo a valores y no a consumo. Sin embargo, esta marca consiguió con este anuncio todo lo contrario: el 29 de noviembre 2018, cuando se publicó en Internet, recibió en ese mismo día 6 millones de visitas y casi 11 millones durante las primeras semanas. Este fenómeno en el cual la publicidad se vuelve viral en un ecosistema mediático es profundamente tratado por Dafonte-Gomez y Martinez-Rolan (2016), otorgando al espectador un protagonismo esencial en la difusión del anuncio.

El tipo de naturalismo afectivo que hemos encontrado en este análisis se convierte en parte de la forma en que IKEA rediseña sus tiendas, catálogos o anuncios, planteando un consumo lúdico que impregna una nueva forma de vida actual, trabajo, ocio y hogar. Sólo las marcas que atiendan a la mente y al corazón establecerán una relación empática y sólida con el consumidor, sobre todo las que vinculen los recuerdos de la marca directamente con las emociones más viscerales, como la felicidad o la tristeza (Rúas y García, 2018). Este nuevo uso simbólico nos compromete afectivamente en la remodelación de las relaciones sociales estableciendo un nuevo orden mercantil basado en la afectividad y la aparente simplicidad funcional (Ledin y Machin, 2018).

La fe mueve montañas, aunque necesita una historia con significado creíble para sostenerla, un discurso capaz de combinar sentidos, razón, emoción e imaginación, que permita la construcción de nuevos mitos, formas de comunicación y necesidad de creer en ideas o marcas (Rúas y García, 2018). Una fe centrada en la mujer, cuya mayor presencia en la última parte del anuncio, la más reflexiva, testimonial y emocional, deviene fundamental como estrategia de visibilidad de las mujeres, público objetivo de IKEA. A pesar del peso y presencia de la voz masculina del speaker, incluso en los dos niños, la que habla es ella, asumiendo un rol más activo.

Los datos obtenidos en este trabajo confirman la influencia de la música y el sonido en la caracterización de una marca comercial, en nuestro caso, IKEA, y cómo las emociones suscitadas en un spot se sustentan en los estímulos sonoros que aparecen en el mismo. Por ello se refuerza la necesidad de tener en alta consideración la música y el sonido como elementos de identidad de marca.

A pesar de que los resultados obtenidos son bastante clarificadores, hay que tener en cuenta algunas limitaciones del estudio, como que la muestra de participantes ha sido muy homogénea, centrada en jóvenes estudiantes del grado de cinematografía, lo que puede originar cierto sesgo respecto al público general a quien va dirigido este audiovisual. 
Calderón-Garrido, D. y Gustems-Carncier, J. Música y sonido en la potenciación de una marca: el caso de IKEA

\section{REFERENCIAS}

Aiello, G. \& Dickinson, G. (2014). Beyond authenticity: A visual-material analysis of locality in the global redesign of Starbucks stores. Visual Communication, 13(3), 303-321. http://doi.org/10.1177/1470357214530054

Alcalde, J. (2007). Música y Comunicación. Puntos de encuentro básicos. Madrid: Fragua.

Bruner, G. C. (1990). Music, Mood, and Marketing. Journal of Marketing, 54(4), 94104.

Calderón, D.; Gustems, J; Martín, C.; Fuentes, C., \& Portela, A. (2020). Emociones en la experiencia artística: claves para el desarrollo educativo y social. Artseduca, 25, 85-101.

Chion, M. (1993). La audiovisión. Introducción a un análisis conjunto de la imagen y el sonido. Barcelona: Paidós.

Cluley, R. \& Nixon, E. (2019). What is an advert? A sociological perspective on marketing media. Marketing Theory, 19(4), 405-423.

Coker, K. K., Flight, R. L., \& Baima, D. M. (2021). Video storytelling ads vs argumentative ads: how hooking viewers enhances consumer engagement. Journal of Research in Interactive Marketing. https://doi.org/10.1108/JRIM-052020-0115

Dafonte-Gómez, A., \& Martínez-Rolán, X. (2016). Del view al share: el papel de la comunicación viral en la transformación del ecosistema mediático. Palabra Clave, 19(2), 501-525. http://doi.org/10.5294/pacla.2016.19.2.7

Díaz-Andreu, M. \& García Benito, C. (2013). Sound and ritual in Levantine art: a preliminary study. En R. Jiménez Pasalodos et al. (eds.), Music and Ritual: Bridging Material and Living Cultures. Berlin: Ekho Verlag (227-256).

Diener, E. \& Emmons, R. A. (1984). The independence of positive and negative affect. Journal of Personality and Social Psychology, 475), 1105-1117.

Edvardsson, B.; Enquist, B. \& Hay, M. (2006). Values-based service brands: narratives from IKEA. Managing Service Quality, 16(3), 230-246.

Escribano, G.; Fuentes, M. \& Alcaraz, J. (2006). Políticas de marketing. Madrid: Paraninfo.

Fedrizzi, L. (2012). Beauty and its perception: historical development of concepts, neuroaesthetics, and gender-differences. Rendiconti Lincei, 23(3), 259-269. 
Calderón-Garrido, D. y Gustems-Carncier, J. Música y sonido en la potenciación de una marca: el caso de IKEA

González-Abarca, A. J.; Ramos-Corrales, J.; Nolasco-García, E. A.; Lara-Flores, A.; Ramírez-Piedras, A.; Márquez-Alcaraz, M. E.; Illan-López, O. C. \& Amaya-G, M. R. (2018). Depresión y suicidio. Salud Jalisco, 1(1), 47-55.

Griffiths, N. K. \& Reay, J. L. (2018). The relative importance of aural and visual information in the evaluation of western canon music performance by musicians and nonmusicians. Music Perception: An Interdisciplinary Journal, 35(3), 364-375.

Gummesson, E.; Kuusela, H. \& Närvänen, E. (2014). Reinventing marketing strategy by recasting supplier/customer roles. Journal of Service Management, 25(2), 228240.

Gustems, J. (2005). Escuchar los anuncios: una aproximación al uso de la música y del sonido en la publicidad televisiva. Eufonia, 34, 91-100.

Halliday, M.A.K. (1978). Language as Social Semiotic: The Social Interpretation of Language and Meaning. Londres: Edward Arnold.

Hernández, C. (2018). Suicidos crecen en fiestas navideñas. Bienestar, 180.

IKEA (29 de noviembre, 2018). Familiarizados [vídeo]. Youtube. https://www.youtube.com/watch?v=grTQHDIcI2w

Isidro, A. \& Moreno, T. (2018). Redes sociales y aplicaciones de móvil: uso, abuso y adicción. International Journal of Developmental and Educational Psychology. Revista INFAD de Psicología, 4(1), 203-212.

Juslin, P. N. \& Sloboda, J.A. (Eds.) (2001). Music and Emotion: Theory and Research. Oxford: Oxford University Press.

Kang, J. A., Hong, S. \& Hubbard, G. T. (2020). The role of storytelling in advertising: Consumer emotion, narrative engagement level, and word-of-mouth intention. Journal of Consumer Behaviour, 19(1), 47-56. https://doi.org/10.1002/cb.1793KANG ET AL.55

Kress, G. \& van Leeuwen, T. (2001). Multimodal discourse. The modes and media of contemporary Communication. Londres: Edward Arnold.

Ledin, P. \& Machin, D. (2018). Forty years of IKEA kitchens and the rise of a neoliberal control of domestic space. Visual Communication, Q(0), 1-23.

Livinsgton, S. R. \& Thompson, W.F. (2006). Multimodal Affective Interaction. Music Perception, 24(1), 89-94.

Machin, D. \& Van Leeuwen, T. (2007). Global Media Discourse. Londres: Routledge. 
Calderón-Garrido, D. y Gustems-Carncier, J. Música y sonido en la potenciación de una marca: el caso de IKEA

Melgar, J. (2019). Análisis de Emociones a través de la voz, desarrollado por Affectivia. https://neuromarketing.la/2017/10/analisis-de-emociones-a-traves-dela-vozl

Nardone, G. \& Salvini, A. (2006). El diálogo estratégico. Barcelona: RBA.

North, A. C. \& Hargreaves, D.J. (1995). Subjective complexity, familiarity, and liking for popular music. Psychomusicology, 17, 77-93.

Norton, M. I.; Mochon, D. \& Ariely, D. (2012). The IKEA effect: When labor leads to love. Journal of consumer psychology, 22(3), 453-460.

Nowack, K. (2018). Unfinished sympathies: Influence of individual temporal orientation on music preferences. Psychology of Music, 47(5), 736-746.

O'Halloran, K. L. (2008). Systemic funcional-multimodal discourse analyis (SF-MDA): constructing ideational meaning using Language and visual imagery. Visual Communication, 74$)$, 443-474.

Palencia-Lefler, M. (2010). Banda sonora de la publicidad televisiva española: formas, géneros y estilos musicales. Comunicación y sociedad, 23(1), 299-318.

Park, M. J., \& Lee, D. H. (2014). Effects of Storytelling in Advertising on Consumers Empathy. Asia Marketing Journal, 15(4), 103-129.

Ribeiro-Cardoso, J. P.; Vieira, L. H. \& Serra, M. J. (2019). ¿Cómo percibimos la publicidad? Antecedentes de la actitud hacia la publicidad e implicaciones en la intención de compra. Revista Mediterránea de Comunicación, 10(1), 203-213.

Rodríguez Bravo, A. (1998). La dimensión sonora del lenguaje audiovisual. Barcelona: Paidós.

Roberts, K. (2005). Lovemarks: el futuro más allá de las marcas. Madrid: Empresa activa.

Rúas, J. \& García, F. J. (2018). Persuasión y neurociencias. Salamanca: Comunicación Social.

Russell, J. A. (1980). A circumflex model of affect. Journal of Personality and Social Psychology, 39, 1161-1178.

Sánchez Porras, M. J. (2013). La persuasión de la música en la publicidad. El ejemplo Coca-Cola. Historia y Comunicación Social, 18, 349-357.

Schubert, E. (1999). Measuring emotion continuously: Validity and reliability of the two-dimensional emotion-space. Australian Journal of Psychology, 51(3), 154-165. 
Calderón-Garrido, D. y Gustems-Carncier, J. Música y sonido en la potenciación de una marca: el caso de IKEA

Sedeño, A. (2011). La música en los comerciales televisivos: el arma secreta. Sinfonía virtual, 18.

Strobel, H. (1990). Claude Debussy. Madrid: Alianza Música.

Van Leeuwen, T. (2017). Immersion. Sound and Vision, 6(2), 136-145.

Verlaine, P. (1999). One Hundred and One Poems by Paul Verlaine. Chicago: University of Chicago

Yang, K. C. \& Kang, Y. (2021). Predicting the Relationships Between Narrative Transportation, Consumer Brand Experience, Love and Loyalty in Video Storytelling Advertising. Journal of Creative Communications, 16(1), 7-26. https://doi.org/10.1177\%2F0973258620984262

Yılmaz, H., \& Enginkaya, E. (2015). Brand followers: motivations and attitudes of consumers to follow brands in social media. International Journal of Internet Marketing and Advertising, 9(1), 3-20. https://doi.org/10.1504/IJIMA.2015.068356

\section{AUTORES:}

\section{Diego Calderón-Garrido}

Doctor en Historia del Arte, Doctor en Tecnología Educativa, titulado superior en Jazz y Música Moderna. Serra Húnter Fellow en la Universitat de Barcelona, Facultad de Educación. Sus ámbitos de investigación giran en torno al uso de la música y el sonido en diferentes ámbitos audiovisuales, así como el papel que dicha música y sonido juegan en la caracterización de los diversos contextos comunicativos. Autor de más de 100 capítulos y libros sobre dichas temáticas.

dcalderon@ub.edu

Orcid ID: https://orcid.org/0000-0002-2860-6747

Google Scholar: https://scholar.google.es/citations?user=0kZGZ48AAAAJ\&hl=es

ResearchGate: https://www.researchgate.net/profile/Diego-Calderon-Garrido

Scopus: https://www.scopus.com/authid/detail.uri?authorId=57192679954

\section{Josep Gustems-Carnicer}

Doctor en Pedagogía, titulado superior de música y licenciado en Geografía e Historia. Es Profesor Titular en la Universidad de Barcelona. Sus ámbitos de investigación giran en torno al uso de la música y el sonido en diferentes ámbitos audiovisuales, así como el papel que dicha música y sonido juegan en la caracterización de los diversos contextos comunicativos. Autor de más de 200 capítulos y libros sobre dichas temáticas.

jgustems@ub.edu

Orcid ID: https://orcid.org/0000-0002-6442-9805

Google Scholar: https://scholar.google.es/citations?user=eWy2oOAAAAAJ\&hl=es

ResearchGate: https://www.researchgate.net/profile/Josep-Gustems

Scopus: https://www.scopus.com/authid/detail.uri?authorId $=55370088300$ 